\title{
Persuading the sick or impaired doctor to seek treatment
}

\author{
Sydney Brandon
}

A recent working party report published by the Nuffield Provincial Hospitals Trust (1996) made a series of recommendations for the improvement and better coordination of existing services. This comes at a time when new and expensive counselling services are springing up everywhere, the most ambitious being the British Medical Association's 24-hour counselling service for doctors and their relatives.

In essence the report reviewed the evidence of stress-related morbidity in the profession and the needs of doctors, and concluded that in terms of the conservation of a scarce resource special services for doctors could be justified (Box 1). They recognised that it was important to reduce avoidable stress, if necessary by changing working conditions and the nature of the job, as well as by providing adequate services for those who fall ill.

The central proposal of the Nuffield report was the creation of a network of independent regional bodies to be responsible for:

(a) reviewing the services available for doctors with health problems

(b) identifying steps that should be taken to improve working conditions where these are found to be unsatisfactory

(c) drawing up recommendations for a longerterm programme of improvements

(d) monitoring progress

(e) providing information about existing services and developments, both local and national,

(f) publishing an annual report.

These regional bodies, they recommend, must be fully independent of local health authorities and providers, in order to establish their impartiality vis-à-vis the interests of employing organisations. It is this recommendation which is probably
Box 1. Reasons for having special services for doctors

There is a need to protect patients

Doctors are a scarce resource which needs to be conserved

Doctors have high morbidity and are inclined to treat themselves

Doctors have special needs regarding confidentiality

As members of a self-regulating profession doctors are responsible for ensuring that sick colleagues are identified and receive appropriate care.

responsible for the deafening silence from the Department of Health.

\section{Initial action}

Ideally any doctor who is experiencing stressrelated problems should be able to consult management, the Occupational Health Service (OHS) or other local resources. Where there is actual illness then the appropriate first stop is the general practitioner (GP), who can arrange more specialised help. Unfortunately, for a variety of reasons, most doctors are reluctant to use these routes.

There is a deeply ingrained fear that admission of vulnerability will result in loss of respect from colleagues and impaired future employment 
prospects. Any service connected with management, including the OHS, is viewed with suspicion, and misunderstanding of the roles both of management and of the General Medical Council (GMC) is common. A surprising number of doctors believe that sickness absence through nervous or mental problems can result in dismissal or referral to the GMC.

Many doctors either do not have a GP or sign on with a local doyen, a partner or someone else with whom they work closely. They are usually unwilling to discuss sensitive matters with these GPs and rely upon informal consultation. From an early stage in their careers doctors begin to selfprescribe for convenience or to avoid embarrassment. This may progress to inappropriate and excessive self-prescription and drugs may be used to conceal symptoms of stress or illness.

Where doctors misuse alcohol or drugs they develop a remarkable capacity to deceive themselves and others but early recognition by colleagues is essential. Once identified colleagues must accept responsibility for ensuring that patients are protected and that the doctor involved receives proper help. However, often colleagues turn a blind eye to the problem and remarkably even some patients will protect the doctor remarks such as 'He's a grand doctor if you can get him sober' are still to be heard. As a result a significant number of doctors in difficulty are unable or unwilling to seek appropriate help.

\section{How to respond to an impaired colleague}

The question arises as to what can be done when a colleague appears to be ill, unduly stressed or showing impaired performance in his work. The GMC requires any doctor who becomes aware that a colleague may be impaired in his capacity to practice to ensure that patients are protected, and the best way of doing this is to ensure that the doctor receives proper treatment and supervision. Failure to do so knowingly may constitute a disciplinary offence.

\section{Junior doctors}

If the doctor is in one of the training grade posts, his educational supervisor has some responsibility for pastoral counselling and the postgraduate dean will usually have available someone with counselling experience. Junior doctors are, however, very fearful of the effect on their future career of 'weakness' and are often convinced that they will get poor references if they have a period of sickness absence or give other indications that 'they cannot cope'. They often turn to peers for advice when they should be seeking advice from more orthodox and experienced sources. A sympathetic colleague, whether junior or senior, may however be able to persuade them to seek more appropriate help or to take sufficient time off to recover.

According to Johnson (1992) $79 \%$ of preregistration house officers (PRHOs) show significant emotional distress at some time during the year and Firth-Cozens (1990) reported a 50\% prevalence of emotional disturbance, with depression in $28 \%$ and with over half of female PRHOs showing clinical depression. All PRHOs are now advised to register with and consult a GP. One adverse consequence of accepting this advice has recently become apparent. A conscientious GP consulted by a PRHO is likely to record in the notes the presence of anxiety, stress, depression or emotional disturbance. Many young doctors take out income protection insurance unaware that if they make a claim in future their GP records will be scrutinised and if any of these terms are recorded then their claim will be rejected as invalid on the grounds that they have failed to declare prior 'psychological illness'. The injustice of this makes it difficult to insist on young doctors consulting their GP unless they are assured that their records will not be used in this way.

\section{Helping a colleague}

Any doctor giving rise to concern should be approached by friends or colleagues willing to share their concern and offer advice. If the advice is followed, and the colleague seeks help from a GP or appropriate specialist, management will usually be possible on an out-patient basis. If admission is required, either because of the nature of the problem or in order to protect patients, then the question arises of whether admission to local facilities is acceptable.

Regardless of the nature of the illness, most people admitted to hospital are acutely embarrassed when, in wheelchairs or pyjamas, they are seen by colleagues or acquaintances. The unusual states of dependence and loss of role cause further distress. For a doctor the possibility of sharing a ward with patients with whom they have a professional relationship, or facing colleagues who 
they fear may be unsympathetic (or excessively sympathetic) produces a fear that subsequent status and relationships will be impaired. Thus, the doctor often wishes not to be admitted to any hospital with which they have a working relationship. In the past, a sympathetic regional or district medical officer could usually facilitate arrangements for admission out of the area, if necessary arranging admission to a private hospital using funds from the staffing budget. The disappearance of these allies and the introduction of charges for extra-contractual referrals may result in both a loss of confidentiality and haggling over costs, which may delay or prevent the admission. It is important to persuade trusts and purchasers that knock-forknock arrangements or special funding are required.

If, for any reason, the doctor remains unwilling to seek help, then a number of alternatives should be considered. All doctors should bear in mind that, regardless of their wish to help or protect a colleague, their first responsibility is to ensure the prevention of harm to patients.

Individual trusts are considering the procedures they wish to operate in non-disciplinary cases involving health or competence problems. Unfortunately, not all trust directors or their medical directors are sensitive to the problems of sick doctors. They will be the first port of call only where the doctor seeking help for a colleague is sure that a sympathetic response will be forthcoming. The same might be said of OHSs. Many trusts do not have well-established OHSs and examples are still occurring where members of such departments make inappropriate references to management.

\section{Recommendations of the Nuffield report}

One of the recommendations of the Nuffield report is that in each locality there should be a key individual who will act as the first point of contact for doctors seeking advice on health problems. In advance of possible implementation of this recommendation there is often a trusted senior, sometimes (but not necessarily) a psychiatrist, to whom it is possible to turn for advice. Such an individual can often exercise persuasion and some degree of authority to convince the doctor to seek help and to act as facilitator. If such an individual is not available or offers advice which is rejected, then the procedures under $\mathrm{HC}$ (92)13 (Department of Health and Social Security, 1986) may be implemented. This circular, entitled 'Prevention of harm to patients resulting from mental or physical disability of hospital or community medical or dental staff', is due for revision, to take into account the new NHS structures.

Known as the 'three wise men' procedure, it depends upon a chairman or committee elected by the local medical community. The chairman may be consulted in confidence by anyone who is worried about a colleague and then may make discrete enquiries, possibly talking to the colleague identified. Problems of proper help-seeking may be resolved at this stage, but if not a trio can be convened consisting of the chairman or nominee, a consultant from the same hospital as the individual causing concern and another from the same speciality. This committee, the 'three wise men', is required to be satisfied that a problem exists and to explore possible solutions. If their advice is accepted, then no permanent record is made, but they will ensure that the doctor's practice is restricted if necessary until the doctor is fit to return to full duties. If their advice is rejected, then they will discuss with the doctor alternatives and take any action necessary to protect patients. This may involve arranging suspension through management and/or informing the GMC. There are comparable provisions for GPs through local medical committees (British Medical Journal, 1986).

\section{General Medical Council}

Any doctor may discuss anxieties about a colleague with the GMC without initial identification. Where appropriate, formal notification of the GMC may be made and is likely to result in reference to the GMC Health Committee, the procedures of which are described earlier in this issue (Kesteven et al, pp. 297-304). Recent legislation has extended the functions of the GMC to provide jurisdiction over doctors whose professional performance may be seriously deficient. These provisions have now been implemented. Here problems may or may not be related to illness but can be dealt with in confidence with emphasis on re-education and rehabilitation.

The disciplinary committee of the GMC is concerned with gross professional misconduct and deals with the 'bad' doctor rather than those who are sick or distressed.

Although primarily concerned with the protection of the public, the GMC carries out its responsibilities with sensitivity and understanding 
and doctors should be encouraged to see this body as one which will be protective of their individual welfare. Unfortunately, it is rarely able to offer the urgent response that is sometimes needed.

\section{Alcohol and substance misuse}

Where the problem is one of substance misuse, including alcohol, the GP needs to be involved and referral to a specialist service arranged. The Doctors and Dentists Group, made up of those in recovery from addiction, provides valuable support groups and recently a treatment service has been established: these can be accessed through the Medical Council on Alcoholism. There is now a national alcohol helpline which gives advice to those concerned about their own or someone else's drinking (Box 2).

\section{National Association for Staff Support (NASS)}

The NASS (within the health care services) is an organisation set up mainly by nurses and hospital chaplains, which organises courses and training in counselling. In many hospitals counsellors are available to offer help to staff. They tend not to be used by doctors but in some localities have been accepted and provide a useful service (Box 2).

\section{National Counselling Service for Sick Doctors (NCSSD)}

When local or national counselling services have been used or refused and the doctor giving rise to concern is still unwilling to seek help, then the NCSSD may be called upon (see Box 2). This organisation was set up in 1985 to provide an accessible, confidential and non-coercive counselling service for doctors unable or unwilling to seek treatment. It is neither a comprehensive service nor one which provides treatment. It is provided by doctors for doctors, none of whom is remunerated by the service. If it was being set up today it is unlikely that the words 'counselling' or 'sick' would be used because the members are not counsellors and many doctors in need of help do not regard themselves as 'sick'.
Box 2. Support agencies

Medical Council on Alcoholism 01714874445

National Alcohol Helpline London: 01713320202 Rest of UK: 0345320202 (all calls charged at local rates)

National Association for Staff Support Grace M. Owen, General Secretary, 9 Caradon Close, Woking, Surrey GU21 3DU

National Counselling Service for Sick Doctors 01715803160 (office hours)

The initial contact may be made by the affected doctor, a close relative or a colleague, and the caller will be asked only the speciality of the doctor causing concern and his general geographical area. No personal details are sought at this stage and the caller is provided with the contact numbers of one or more national advisors from the same speciality but from a different geographical area. If the caller requests details of an adviser from a different speciality or from a specified geographical area, these will be provided.

If the caller is not the doctor involved, the adviser has to be given details of how to make contact and be told the nature of the problem. Contact is then made by telephone and requires a high degree of tact and sensitivity. The doctor is often shocked, sometimes angry and frequently demands details of the informant, which will not be provided. After this initial response it is surprising how few will terminate the contact, the vast majority agree to continue and many are clearly relieved to have the opportunity to discuss their problem.

If the initial approach is rejected or if advice is offered and rejected, the doctor is provided with the adviser's contact numbers and encouraged to get in touch after further reflection. If within a period dependent upon the judgement of the adviser, but not exceeding four weeks, there is no further contact, then the adviser tells the original informant that no progress has been made and suggests alternative sources of help. The informant will also be reminded of the need to protect patients and of possible actions which might be needed. 
Once a dialogue is established, the adviser, who is always an experienced practitioner with a reputation for helping colleagues, tries to clarify the problem and discuss possible sources of further assistance. The adviser's role is not that of a longterm counsellor or provider of solutions. Their main task is to help the doctor acknowledge, if appropriate, the existence of a problem, and to consider the best means of securing help. Very commonly the problem falls within the sphere of psychiatry and the adviser can contact the Secretary of the Royal College of Psychiatrists and be provided with the names of psychiatrists from the College list who will provide advice and, if necessary, treatment. Once the psychiatric counsellor accepts responsibility for continuing care, the adviser may withdraw but often offers some continuing contact.

Many psychiatric counsellors are now under pressure from their trusts to formalise such extracontractual referrals or referrals of private charges, particularly where admission is involved. Since this is contrary to the ethos of a service which is provided for doctors by doctors without charge, it is being resisted but the problem is becoming more difficult to deal with.

The numbers referred to the service have been gradually increasing and now total around 500 per year. There is still a problem of making the service widely known. Despite regular discrete advertisements on the salaries page of the British Medical Journal, postgraduate lectures and the circulation of pamphlets to clinical tutors and postgraduate centres, studies at the Tavistock (Hale \& Hudson, 1992) and by Silvester et al (1994) have shown that the existence of the service is largely unknown to the majority of doctors.

The implementation of the Nuffield recommendations may change this as the service is supported by 120 national advisers from all specialities and parts of the country. These advisers are nominated by the appropriate College or in the case of GPs, the local medical committee. All are experienced and usually have a reputation for being approachable by colleagues in need. The College list of psychiatric counsellors includes nearly 200 psychiatrists, but a better geographical and psychiatric speciality spread is needed, particularly of those with expertise in the drugs and alcohol field. Women and different ethnic groups are also under-represented.

The service has from the beginning been keen to emphasise complete confidentiality, which can never be unconditionally guaranteed. Strict criteria have been laid down for circumstances in which confidentiality might be breached but the need for them has not arisen.

\section{Future developments}

The preoccupation with confidentiality has prevented the recording of information which might enable the service to evaluate its effectiveness. Efforts are now being made to establish a database for future referrals while maintaining confidentiality.

At times advisers have been inclined to embark upon long-term supportive counselling when it might have been better to refer to a specialist.

It has been suggested that the development of counselling services with skilled non-medical counsellors and 24-hour access will remove the necessity for the NCSSD. Many believe that the maintenance of a doctor-only service, with doctors talking to doctors, is still necessary and no matter how many services are developed there will still be those who are reluctant to seek help. There is room for a variety of services and a degree of choice. A particular strength of the NCSSD is its independence. The members of the National Management Committee are nominated by various bodies but act in their own right.

\section{Special needs in treating doctors}

Although drugs are commonly indicated most doctors who consult the service are grateful for the opportunity to discuss their problem and need help in developing coping strategies. Because of their knowledge of drugs and other treatments doctors may be more questioning of the therapies offered to them. They have a keen awareness of adverse effects and despite their knowledge have low levels of compliance. However, they cannot be assumed to have a good understanding of the subjective nature of their disorder. Doctors not infrequently have prejudices about mental illness and often cannot relate aspects of their own feelings or behaviour to their illness. Thus, they may acknowledge current depression but insist that their low self-esteem is due to their own inadequacy rather than to illness. The risk of suicide appears to be greatest in those whose condition has been unrecognised and who refuse to engage in treatment.

There is a risk in continuing to treat doctors as colleagues rather than as patients and allowing them to take decisions about their own management which they may not yet capable of doing. While a sick doctor deserves respect as a colleague, the treatment process is not a peer consultation and the treating doctor must accept responsibility for the process while recognising the greater 
imperative to provide full information and secure proper consent.

One of the problems doctors have in seeking help is the myth of indispensability. They often feel that they alone can treat their patients and that if they are not available there will be no one to assume their responsibilities. Often there is an element of reality in such a fear. The treating doctor may collude in allowing the sick doctor to remain at work when sick leave would be more appropriate.

\section{Conclusions}

Doctors are a scarce resource and a high-risk group in terms of morbidity and mortality from stressrelated conditions. It is justifiable to make special arrangements for their care as there are serious impediments to using existing services. Some doctors are unable or unwilling to seek help and for them a doctor-to-doctor service such as the NCSSD offers an important resource in securing help and in protecting patients.

\section{References}

British Medical Journal (1986) LMC scheme to help sick doctors. British Medical Journal, 293, 899-900.

Department of Health and Social Security (1986) Prevention of Harm to Patients Resulting from Physical or Mental Disability of Hospital or Community Medical or Dental Staff (HC(92)13). London: DHSS.

Firth-Cozens, J. (1990) Sources of stress in women junior house doctors. British Medical Journal, 301, 89-91.

Hale, R. \& Hudson, J. (1992) The Tavistock study of young doctors: report of the pilot phase. British Journal of Hospital Medicine, 47, 452-464.

Johnson, W. D. K. (1992) Stressors and Stress Outcomes in Junior House Officers. PhD thesis; United Medical and Dental Schools of Guy's and St Thomas's Hospitals.

Kessel, N. (1996) Ill doctors. Psychiatric Bulletin, 20, 577-579.

Nuffield Provincial Hospitals Trust (1996) Taking Care of Doctors Health. London: Nuffield Provincial Hospitals Trust.

Silvester, S., Allen, H., Withey, C., et al (1994) The Provision of Medical Services to Sick Doctors: A Conspiracy of Friendliness? London: Nuffield Provincial Hospitals Trust.

\section{Multiple choice questions}

1. A doctor who becomes ill:

a should consult the general practitioner with whom he or she is registered

b with a psychiatric disorder should inform the General Medical Council

c and is tempted to self-prescribe should be discouraged d must consult the Occupational Health Service

e and whose capacity to practise may be

impaired needs to have steps taken to prevent any harm to patients, preferably by ensuring that he or she receives proper treatment and supervision.

2. If concerned about a colleague's fitness to practice:

a confidential and informal advice may be sought from the GMC

b the employing authority, such as the trust chairman or a senior manager, should be informed at once

c this should be discussed at the appropriate medical staff committee

d a friendly approach and encouragement to seek help is often the best first step

e the chairman of the 'three wise men' (or the local medical committee equivalent) may be consulted for advice.

3. The following statements are true:

a most junior doctors experience stress-related symptoms amounting to 'significant psychiatric morbidity' at some time during training

b educational supervisors are not responsible for pastoral care and cannot be expected to advise on mental health or other medical problems in their trainees

c the function of the National Counselling Service for Sick Doctors is to deal with doctors who appear unable or unwilling to seek treatment

d a doctor who has apparently recovered from a severe affective illness or alcoholism should be discouraged from returning to clinical practice

e women overseas doctors are among the highest risk groups for suicide.

4. The Nuffield Working Party on the care of sick doctors recommended:

a independent regional bodies to review services available to doctors with health problems

b that local measures should be taken to identify adverse working conditions and the steps necessary to remedy them

c sick doctors should be required to seek help from their local OHS

d the strengthening of the 'three wise men' system

e that any doctor suffering from psychiatric illness or disability should be referred to the Health Committee of the GMC. 
5. The National Counselling Service for Sick Doctors: a offers a confidential, non-coercive service to doctors who are unable or unwilling to seek help for a potential impairment of their competence

b has national advisors from all specialities

c has access to over $\mathbf{2 0 0}$ psychiatric counsellors who are accessed through the College

$\mathrm{d}$ is a service for doctors by doctors none of

\begin{tabular}{|c|c|c|c|c|c|c|}
\hline \multicolumn{7}{|c|}{ MCQ answers } \\
\hline 1 & 2 & & 3 & & 4 & 5 \\
\hline a $\mathrm{T}$ & & $T$ & & $\mathrm{~T}$ & a $T$ & a $\mathrm{T}$ \\
\hline b $F$ & b & F & b & F & b $\mathrm{T}$ & b $\mathrm{T}$ \\
\hline c $\mathrm{T}$ & c & F & c & $\mathrm{T}$ & c $\mathrm{F}$ & c $\mathrm{T}$ \\
\hline d F & d & $T$ & d & F & d $T$ & d $T$ \\
\hline e $T$ & e & $T$ & e & $\mathrm{T}$ & e $F$ & e $F$ \\
\hline
\end{tabular}
whom receives remuneration for their work in the service

$e$ is managed by the BMA and the GMC. 